\title{
La opinión pública interior en un sindicato histórico de clase: paradojas de la reminiscencia y modelos cognitivos
}

\author{
Fermín Bouza
}

Universidad Complutense de M adrid. D epartamento de Sociología. M adrid. Spain

\section{Resumen}

La definición de la situación en el interior del sindicato es un hecho colectivo, que tiene, sin embargo, un núcleo más activo en los sectores más próximos al centro (cargos sindicales y delegados afiliados). Esa definición se hace desde unos hábitos cognitivos históricos enmarcados en toda una cultura sindical que toma la forma de ideología (postulados sistemáticos) en los escritos de la organización y genera una opinión pública interior. Cambiar o no esa cultura es un vasto problema estratégico cuyo alcance desborda este ámbito analítico.

Palabras clave: modelos cognitivos, hábitos cognitivos, opinión pública, cultura sindical.

Abstract. Public opinion inside a historical labour union: reminiscence paradoxes and cognitive models

The definition of a situation inside a labour union is a collective fact which has, however, a more active nucleus close to the central sectors (hierarchy, member delegates). T his definition is reached through historical cognitive habits which are inside every labour unions culture and gives rise to an ideology (sistematic postulates) in the organization writings and produces an internal public opinion. To modify or not modify that culture is a broad strategic question which is outside this analysis.

Key words: cognitive models, cognitive habits, public opinion, labour unions culture.

\section{Sumario}

\section{Introducción}

2. Cultura, discurso y opinión pública

3. Los procesos de modernización cultural

4. Autoimagen y construcción de la real idad cultural como determinante de la opinión: acción y conciencia de clase, guión cognitivo
5. Errores funcionales. Centro y periferia del grupo

6. Acción colectiva, interés, reminiscencia e identidad

7. La opinión interior como proceso colectivo

Bibliografía 
La intervención sociológica quiere ser el método que corresponde prioritariamente al estudio de las conductas colectivas por las cuales las formas de organización social son producidas como resultado de los conflictos sociales por el control y la apropiación de los patrones culturales a través de los cuales una colectividad construye de manera normativa sus relaciones con su entorno.

(Alain Touraine, La M ethode de I'Intervention Sociologique, p. 14)

Europa no deci dió aceptar el lenguaje de la poesía romántica, ni el de la política socialista, ni el de la mecánica galileana. Las mutaciones de este tipo no fueron un acto de voluntad en mayor medida que el resultado de una discusión. El caso fue, más bien, que Europa fue perdiendo poco a poco la costumbre de emplear ciertas palabras y adquirió poco a poco la costumbre de emplear otras.

(Richard Rorty, Contingencia, ironía y solidaridad, p. 26)

\section{Introducción}

Por una serie de circunstancias más bien complejas este artículo ha ido demorando su publicación hasta ahora. No es tarde aún, y espero que sea útil para reflexionar sobre los temas que incluye. Este trabajo es un intento de explicar la génesis y la estructura de la opinión pública en organizaciones formal es de carácter sindical, así como las funciones que esta opinión cumple en el mantenimiento de los incentivos col ectivos que pudieran servir para mantener la cultura (ideología en sentido fuerte) de estas organizaciones. En el caso que me ocupa se trata del sindicato U GT (Unión G eneral de Trabajadores) para el que he realizado un conjunto de investigaciones de diverso tipo (F. Bouza, 1989a y b; 1990), que ahora amplío con diversas calas en aspectos que no han sido explorados, como éste que constituye el objeto del trabajo.

A partir de 1987 se planteó una investigación cuantitativa y cualitativa por la Fundación Largo C aballero (dirigida por M anuel Ventura cuando se inició la investigación y por Sebastian Reyna cuando se concluyó) para conocer cuál era la opinión pública interior del sindicato sobre aquellas cuestiones que podían afectar a la afiliación y cuáles eran, en general, las razones por las que una parte importante de los trabajadores no se afiliaban a los sindicatos. Esta larga investigación fue continuada, en cierto modo, con el análisis del congreso de U GT y con la encuesta electoral de las elecciones sindicales, que tuvieron al gunos aspectos conflictivos relativos a los preavisos generalizados presentados por CCOO y que dieron lugar a un juicio de gran interés sociológico. Todas estas investigaciones fueron dirigidas por mí, y en su realización colaboraron o nos ayudaron de diverso modo al equipo de la Fundación (M aría Teresa Vargas, Almudena A senjo, Francisco Borges), los sociólogos Luis G arrido, M iguel Requena, Juan Jesús G onzález y otros (entre ellos, el equipo «Arias y Asociados»). El presente trabajo continúa, a un nivel más complejo de conceptuación, esas investigaciones.

$H$ ay que decir que sin U GT y sin la FLC el inicio de estas investigaciones no hubiera sido posible, con lo cual queda relativizado el aspecto más crítico que 
pueda tener este trabajo, puesto que aquéllos que son analizados aquí son los mismos que han pedido este análisis, lo cual significa que están trabajando en el sentido de mejorar las condiciones representativas de los trabajadores. Probablemente muchos de ellos no concuerden con las tesis de este trabajo ni de los anteriores, y hacen muy bien, porque no hay cosa más estéril que estar de acuerdo en aquello que está pidiendo un debate real. En épocas de cambio como la nuestra, las condiciones que hacen posible y necesario cualquier debate están debilitadas por la urgencia de la misma situación, que o bien incita a conclusiones precipitadas o a resistencias absurdas, aunque como veremos las resistencias pueden no ser tan absurdas como en una primera aproximación pudieran parecer.

No conozco ninguna investigación interior a un sindicato de clase histórico de las características de U GT, y este conjunto de trabajos aportan una novedad a la bibliografía sobre el tema de las organizaciones formales de interés y al análisis de algunos de sus más interesantes problemas. En la lectura actual, debe entenderse que son datos de unos tiempos en los que U GT mantenía un pulso con el PSOE por su autonomía, y en los que N icolás Redondo ocupaba la Secretaría General del Sindicato. No he querido modificar la bibliografía usada y citada porque es la que se corresponde a aquel momento y la que aporta lo que los americanos llaman el frame o marco de la investigación: lo que hace posible entender ciertas cosas de ella, e interpretarla.

\section{Cultura, discurso y opinión pública}

Entiendo por paradojas dela reminiscencia aquellas contradicciones que se plantean a toda organización entre su cultura tradicional de sustentación (incentivos col ectivos de identidad) y las necesidades de adaptación: Ia remi ni scencia es la presencia o el regreso recurrente de esa cultura tradicional, que cumple funciones autoconservadoras de identidad y cohesión, entre otras.

La cultura de la organización es el factor determinante, en mi criterio, de la opinión expresada o pública de sus afiliados. D efinimos cultura, en los términos clásicos de Sir Edward B. Tylor, como «the complexe whole», la totalidad compleja producida y/o adquirida por el hombre en cuanto miembro de la sociedad, y habría que decir, a nuestros efectos, producida y/o adquirida por las organizaciones. Esa totalidad compleja que incluye tantas cosas y que, por ello, ha sido reducida por los antropólogos a lo largo de los últimos decenios a aspectos parciales (lenguaje, símbolos... ), la reducimos también aquí al sistema de crencias que comparten los miembros de una organización formal de carácter ideológico: un sindicato, en nuestro caso. La reducción metodológica de la definición tyloriana de cultura permite conservar el espíritu totalizador de la definición pionera de Tylor y aplicarla sectorialmente.

El mantenimiento de ciertas creencias puede entenderse como supervivencia (Tylor) o como funcionalidad ( $M$ alinowski), pero también, sin entrar en el debate metodológico, como supervivencia funcional: aspectos de una cultura tradicional que perduran funcionalmente y que, añadimos, se expresan 
verbalmente bajo la forma de oposiciones que «cierran» el espacio creencial en opciones dicotómicas muy rígidas, como veremos. En este sentido es en el que vamos a tratar de mostrar la génesis de la opinión pública interior de un sindicato como un proceso cognitivo colectivo que ha generado modelos, gui ones 0 mapas cognitivos di cotómicos: reminiscencias de orígenes o mitos genéticos que siguen cumpliendo una función, cuya valoración en términos de eficacia y acción colectiva trataremos de hacer.

La definición de cultura como «el conjunto de información no hereditaria acumulada, conservada y transmitida por las diversas colectividades de la sociedad humana» (Y. Lotman, 1973: 71) nos permite interpretar la «totalidad compleja» en términos informativos, y entender la cognición colectiva como proceso de selección y elaboración de información.

N o postulamos una mentalidad grupal en su sentido más esencialista 0 determinante, sino unos hábitos cognitivos y unas conductas típicas a los que eventualmente podemos llamar mentalidades en el marco de una reconceptuación del término, y, desde un uso empírico, proceder a las falsaciones oportunas. Tales hábitos cognitivos y conductas típicas están fundados en una tradición de aprendizaje común (en el marco creencial de una cultura compartida) y conducen a unos usos verbales y conceptuales en el marco restringido de un sistema de oposiciones que marcan el ámbito de la creencia propia y ajena: la definición de la frontera entre el grupo y los otros.

El discurso grupal está limitado por ese sistema de oposiciones que la cultura del grupo ha generado, y muestra los estereoti pos grupales como formas cognitivas (H . Tajfel, 1984: 155 y s.). C omo dice Tajfel, «no hay duda de que el contenido de los diversos estereotipos tiene sus orígenes en tradiciones culturales, que pueden estar relacionadas o no con experiencias comunes, pasadas o presentes, generalizadas en exceso. Pero, quizás lo que es más importante es su estructura y su función. Como Gordon Allport (en The nature of prejudice, 1971 (1954)) y muchos otros señalaron, los estereotipos surgen de un proceso de categorización. Introducen simplicidad y orden donde hay complejidad y variación casi al azar. Solamente nos ayudan si las diferencias difusas entre grupos se transforman en diferencias claras, o si se crean nuevas diferencias donde antes no existía ninguna. Por supuesto, los estereotipos representan tendencias hacia la simplificación más que hacia dicotomías abruptas; en otras palabras, en cada situación relevante realizaremos tanta simplificación estereotipada como podamos, sin violentar innecesariamente los hechos. Pero hay sobrados indicios de que, induso cuando los hechos se vuelven contra nosotros y destruyen las confortables y útiles di stinciones, todavía encontramos maneras de mantener el contenido general de nuestras categorías. (cursivas mías) (H. Tajfel, 1984: 160).

Aún matizando la afirmación de Tajfel de que «los estereotipos representan tendencias hacia la simplificación más que hacia dicotomías abruptas», el conjunto del párrafo, que resume las investigaciones sobre el tema, encuadra bien la cuestión que aquí planteamos. D ecía que matizaba esa afirmación de Tajfel, y lo hago al menos en el sentido de que, en el caso que nos ocupa, parece fun- 
cionar un sistema de oposiciones bastante abrupto que luego veremos, creado por los estereotipos que fundan la cultura del sindicato.

Vamos a ver en qué medida esas categorizaciones fundadas en estereotipos determinan un proceso de cierre organizativo del modo y manera en que aparece en las encuestas realizadas en el interior del sindicato.

El discurso que emana de sus afiliados (delegados o no) expresa vivamente ese sistema de oposiciones (F. Bouza, 1989a y b, 1990c) y sistematiza la información organizativa desde sus comienzos: tal información, elaborada en la historia y en la acción colectiva, es la cultura del sindicato entendida como sistema de creencias. La opinión pública interior está determinada por este marco cultural que aporta un diccionario de usos en el que los términos políticos (entre otros) habituales tienen las entradas léxicas pertinentes al mantenimiento de tal cultura como modo de interpretar la realidad, entradas léxicas 0 acepciones que se renuevan de forma ad hoc. Este proceso de construcción de la realidad a través de interpretaciones colectivas muy regladas (orgánicas) en el marco de una cultura tradicional, conduce a una tensión permanente entre tal cultura orgánica y el mundo externo, tensión que se expresa, como veremos, en forma de opiniones defensivas hacia el exterior, dificultando la modernización de las organizaciones.

Sin embargo, el que la adaptación o modernización esté obstaculizada por prejuicios defensivos no quiere decir que tales prejuicios, los estereotipos que conforman y la cultura de la que proceden y a la que refuerzan, no cumplan un papel muy productivo para el mantenimiento de una organización: no se puede dar como seguro el que lo que llamamos modernización de una organización no conduzca, finalmente, a su crisis y desaparición. Y aún considerando muy correcta y sugerente la posición de J on Elster (1988: 2.232) que cito en sus propias palabras ( «La idea de errores útiles, equivocaciones afortunadas y prejuicios beneficiosos atrae a cierto tipo de pensador, a aquél que está fascinado por lo contraintuitivo, las elaboraciones paradójicas y perversas de la mente humana y de las sociedades humanas. Según mi propia experiencia personal, esta fascinación puede convertirse en una obsesión, de modo tal que uno empieza a considerar axiomático que los esfuerzos deliberados nunca tendrán éxito y que el objetivo sólo se logrará por accidente, como subproducto, o por efecto de algún error afortunado. D e ahí a afirmar la creencia implícita o explícita de que estos mecanismos perversos de alcanzar objetivos puedan ser explicados por su tendencia a producir tales felices resultados hay un sólo paso»), aún siendo esencialmente cierto todo esto, no es menos cierto que efectos relativamente positivos se pueden derivar de acciones erróneas. $Y$ digo «relativamente» porque la positividad de la autoconservación de una organización en sus términos actual es es discutible desde diversos puntos de vista, por más que el mero hecho de la estabilidad y la conservación temporales produzcan lo que puede ser un espejismo social. ¿O quizá no? Es preciso estudiar cada caso concreto para poder contestar con rigor a esta última duda, aunque la decisión de cambiar o no la cultura organizativa (la ideología en sentido fuerte 0 amplio, incluyen do usos y costumbres: mentalidad materializada o reglada en normas 
de circulación creencial definidas por esa cultura abarcadora) sea siempre difícil, penosa, compleja, y tienda a ser apartada de las preocupaciones del día como «cuestión metafísica» 0 algo similar, reforzándose así la tendencia general al mantenimiento de la definición de la situación, como es normal en toda organización de cualquier tipo.

\section{Los procesos de modernización cultural}

La cuestión final que se plantea en la investigación realizada y en las investigaciones futuras, es la de las organizaciones sindicales (y políticas en sentido estricto, y aún de las organizaciones en general) enfrentadas a un proceso de modernización que implica una sustitución de conductas y de creencias profundamente arraigadas en sus miembros o afiliados: un proceso de modernización en los términos en que la sociología le dio a tal concepto en las últimas décadas.

El concepto de modernización ha sido polémico, y sigue siéndolo, sin que su exacto significado se haya fijado para siempre y por encima de tal polémica. En el marco de ese debate, el problema principal es aquél que aparece cuando se pretende, explícita o implícitamente, mostrar la universalidad de un model o modernizador por encima de la propia dinámica de las sociedades concretas (A. Touraine, 1989). En el sistema cultural, por usar la terminología parsoniana (sin que ello signifique un acatamiento de sus tesis centrales) se produce una tensión hacia el mantenimiento de patrones que nosotros vamos a interpretar como mantenimiento de creencias, y esa tensión creencial está sometida también a la polémica del modelo único, como ocurre con la economía o con la sociedad en su conjunto.

Temas del día, como son el del islamismo como religión de estado o como religión omniorientativa (parte central de las culturas árabes), replantean la cuestión de la adecuación creencial al conjunto de valores (acciones creenciales) del modelo occidental, o el mantenimiento de la cultura islámica como eje del proceso modernizador. En este debate, las posiciones indigenistas y cosmopolitas aducen poderosos argumentos en favor de sus tesis, y de nuevo se vitaliza la polémica central de la década de los años sesenta sobre los modelos de desarrollo. En el caso que nos ocupa, no se trata de una cultura nacional que sustente un proceso progresivo o regresivo de adecuación o inadecuación a la modernidad, sino de la cultura interior de una organización que también tiene un papel determinante en la adaptación o inadaptación de un sindicato histórico de clase de esas características a los procesos de cambio social acelerado que se están produciendo. La racionalidad del sistema creencial o cultural, y de los hábitos o acciones de una organización sindical se confrontan hoy con una creciente tendencia a la unanimidad en torno al modelo de razón que debe prevalecer en los países occidentales y aún en el mundo: esta mundialización del modelo de racionalidad óptima está produciendo tensiones adicionales a las ya existentes en toda organización necesitada de una transformación de su opinión interior: los cambios tienden a verse 
como imposiciones 0 agresiones, y la actitud defensiva o de cierre parece inducir un modelo «nacionalista» (metafóricamente hablando) en este tipo de organizaciones.

Con frecuencia, al uso del concepto de racionalidad se le imputa un etnocentrismo que se presenta como evidente: «Los "universales cognitivos" no son otra cosa que la transformación de las creencias occidentales» (J . Lave, 1988: 186; véase también M. Sahlins: 1976 (1988), 1981). Sin embargo, la tendencia a buscar diversos universales se ha hecho firme en la lingüística (Chomsky) y en la antropología (M ary D ouglas), siendo ahora la metodología cognitiva (científicamente interdisciplinaria) la que busca sus model os de proceso universalizables. En cierta manera, esta tensión entre racionalidades universales y particulares expresa muy significativamente problemas que hoy aparecen como centrales en la dinámica social, y esta centralidad de la cuestión debatida entre racionalidades o lógicas universales y locales es vivida, en el ámbito político que nos ocupa, hacia el tema del acatamiento o no de lo que se ha venido llamando «un nuevo orden mundial»: se hace una interpretación netamente política de la cuestión, y el debate deriva hacia lo política de tal forma que oscurece la cuestión de la modernización cultural del sindicato. En términos de Ludolfo Paramio (1988: 33), la alternativa a los problemas sindicales es «una nueva cultura política y una nueva cultura sindical que acentúen en términos racionales el valor de la solidaridad: lo que podríamos llamar "un altruismo utilitarista"».

La cultura que se reclama para hacer frente a la nueva situación tiene más que ver con el liberalismo histórico que con los valores comunitarios tradicionales de la clase obrera. Yo mismo (F. Bouza, 1990c) he confrontado estos valores de una racionalidad nueva de raíz utilitaria con esos valores tradicionales, y he creído ver también en éstos últimos un obstáculo creciente para realizar el proceso adaptativo. El egoísmo racional que se propone (L. Paramio, 1988: 34) como alternativa a la disolución de la identidad obrera tradicional y a los egoísmos particulares que emergen sobre ese vacío, es una conceptuación que aparece demasiado abrupta (e históricamente significada) en el marco de una cultura fundada sobre lo comunitario, por más que contenga elementos mucho más sólidos para la nueva acción sindical que la cultura en declive. $\mathrm{N}$ icolás Redondo, secretario general del sindicato en el momento de la investigación, lo expresa vivamente: «EI progreso en sentido solidario siempre se entendió como un proceso en el que la dimensión colectiva prevalecía sobre el egoísmo individualista, pero se nos presentan ahora estas aspiraciones como antitéticas con una sociedad moderna».

La cuestión reside en la posibilidad o no de adopción por las organizaciones sindicales de un recambio cultural con esos indudables fundamentos simbólicamente antiobreros. Posi bilidad se refiere aquí al marco cultural receptivo de estas nuevas elaboraciones teóricas: en qué medida es posible un cambio de racionalidad partiendo de la ideología y de la cultura históricas, y en qué medida, si no es posible ese cambio, estas organizaciones están abocadas a la permanencia en esa línea de declive que al gunos postulan como cierta y que, en 
todo caso, algunosíndices (baja general de la afiliación en Europa) señalan, al menos coyuntural mente.

Esta nueva retórica racional-utilitaria ¿es un modelo de modernización cultural adecuado o es la forma ideológica de una renovada estrategia de dominio, como algunos sindicalistas piensan?, ¿en qué media la opinión pública sindical en el marco del sindicato analizado por mí en los últimos años contiene elementos receptivos o en qué medida está fundada sobre dicotomías categóricas fundadas sobre estereotipos muy rígidos? El análisis de al gunos aspectos de esta opinión pública sindical que ahora hago aquí trata de dar cuenta de ello.

\section{Autoimagen y construcción de la realidad cultural como determinante de la opinión: acción y conciencia de clase, guión cognitivo}

Construida por oposición, la autoimagen de los trabajadores de este sindicato vendría dada por los conceptos inversos a los que ellos atribuyen abrumadoramente (F. Bouza, 1989a, 1990c) a los trabajadores no sindicalizados: apáticos y sin conciencia de clase. Esto es una atribución. Los mecanismos de atribución, en sentido sociológico y psicosociológico, son aquellos que procuran un orden en el entorno mediante la asignación a los demás de ciertas características u otras cuestiones más fácticas: una forma de reducir la imprevisibilidad del entorno y de facilitar su comprensión. Realizada desde inferencias más o menos fundadas empíricamente, la atribución es un orden ad hoc que prolonga las creencias y les da consistencia real en un mundo construido desde uno mismo: «las categorías social es tienden crecientemente a ser un tópico de la investigación en sí mismas. Los psicólogos sociales se han centrado sobre los procesos cognitivos subrayando la categorización y sus consecuencias. ¿Cuál es el mecanismo cognitivo implicado en la categorización? ¿Cómo construye la gente el mundo social dentro de las distintas agrupaciones? Y, dado que una categoría ha sido aplicada, qué efecto tendrá sobre la percepción de la gente o el conocimiento? En esta tradición, la categorización es vista como un fenómeno natural similar a la respiración; la gente transforma automáticamente el detritus contaminado de su entorno físico y de su realidad social en una forma simplificada y fácilmente asimilable» (J. Potter y M. Wetherell, 1987: 116). En este sentido, apáticos y sin conciencia de clase limita el mundo conocido a una dicotomía pedagógica: el mundo de los activos frente a los apáticos, y el mundo de los trabajadores con conciencia de clase frente a los sin conciencia de clase. Las dicotomías más específicas no se detienen ahí, pero estas dos son las más expresivas. Se ha producido en esta operación atributiva una simplificación del mundo que, al tiempo que facilita su conocimiento, lo deforma, y es esta deformación producida en estos procesos atributivos, categorizadores y estereotipificadores, la que dificulta la adaptación a las transformaciones sociales y la evolución cultural y de la opinión interior de la organización.

Aunque nacidas en otra tradición, podemos considerar a las teorías de la atribución formando parte del grupo de tradiciones que analizan los procesos 
de construcción social de la realidad desde diversas perspectivas metodológicas y diferentes tradiciones, a veces sin ninguna relación, como la etnometodología, las sociologías de la vida cotidiana de diverso origen, la sociología cognitiva y las diversas áreas de la psicología social que estudian temas de esta índole, entre otras.

La percepción del mundo externo aparece fundada sobre atribuciones (definiciones estables de los demás) cuya modificación trastorna al sujeto y le obliga a reestructurar sus puntos de vista (sus atribuciones). En nuestro caso, si el trabajador sindicado llega a entender que los trabajadores no sindicados no necesariamente son «apáticos» y «sin conciencia de clase», el orden atributivo se ve alterado y se producen fenómenos que trataremos de evaluar.

En el proceso de interpretación de un acontecimiento del mundo (¿cómo son los otros trabajadores?, p.e.) se produce una entrada de información individual y/o colectiva (cualquier suceso que exija contestar a esa o a otra pregunta) que es puesta en relación con lo conocido (con la información ya interpretada, con la cultura, con el sistema creencial y valorativo): «a interpretación es el acto de relacionar una entrada nueva de información con lo que ya se conoce» (A. Sanford, 1990: 469). La elaboración de esa entrada informativa o de ese estímulo-pregunta se produce en el interior de un sistema cultural que tiende a la dicotomización: la opinión sindical se expresa en un marco cultural atributivamente dicotomizador. Este complejo de «cul pas y justificacioness (J. Potter y M. Wetherell, op. cit., p. 116) que es el proceso cate gorizador, orienta la acción discursiva hacia la didáctica cultural, y reproduce la cultura de origen en esos procesos atributivos. La cultura, así, se recrea constantemente en el discurso dicotómico (en este caso) y es construida y reconstruida en esta interpretación permanente de la información de entrada que se pone en relación con el núcleo cultural básico. Estamos ante guiones o mapas cognitivos que están fundados en una cultura construida sobre estereotipos y dicha cultura incluye sólidos sistemas de creencias, tema este que ha ocupado el interés de los científicos sociales y aún de los filósofos (R. P. Abelson, 1973).

La oposición activo/pasivo simboliza el carácter transformador de la organización sindical y sitúa al margen de ella al conjunto de posibles afiliados no dotados para la acción, de tal manera que al tiempo que se identifica a la orga nización con ese concepto y sus derivaciones prácticas, se limita a la población de trabajadores activosel trabajo sindical, en un trueque de identidad (acción) por restricción cultural y afiliativa: el incentivo colectivo de pertenecer a un grupo de acción dotado de conciencia de clase es superior a las posibilidades expansivas de la organización. Se genera así una cultura de la acción construida sobre una restricción excesiva. Como el concepto acción se ha adquirido en el marco de las luchas obreras históricas y está dotado de un halo semántico (un campo semántico) que incluye semas como enfrentamiento, violencia, lucha de clases, etc., la percepción de tal acción por los trabajadores no sindicados se resume en la frase shay un sentido ilegal de estar afiliados», que expresa la opinión del conjunto de trabajadores no afiliados estudiados por nosotros 
(F. Bouza, 1990C). La cultura de la acción tiene una profunda raíz simbólico-religiosa: véase la al egoría de la acción en el inventario iconográfico de C esare Ripa (1602) reproducida en J. L. M orales, 1984: 16, y descrita por J. E. Cirlot, 1978: 51:

[... ] no debe extrañar que C ésar Ripa, en su Iconología, representara a la «acción virtuosa» en una suerte de asimilación a las altas imágenes de san M iguel Arcángel, como guerrero armado con coraza dorada, que sostiene en una mano un libro y en la otra una lanza, en ademán de clavarla en la cabeza de la enorme serpiente de la que acaba de triunfar. La cabeza del Vicio, que tiene bajo el pie izquierdo, completa la alegoría. En consecuencia, toda lucha o victoria en el plano material tiene su correspondencia en el dominio del espíritu, como, según la tradición islámica, la «guerra santa» (lucha contra los infieles con las armas en la mano) es mera imagen de la «gran guerra santa» (lucha que sostiene el fiel contra los poderes del mal).

Sobre la vita activa hace una interesante reflexión Albert H irschman (1986: 14-16) en el contexto de las transformaciones semántico-sociales de la oposición público/privado. En este mismo contexto, la acción sindical es, además de heredera de las mitologías religiosas de la acción, la alternativa de los trabajadores al individuali smo naciente y a sus vertientes públicas: la acción popular en el terreno de lo público (sobre público, privado y temas conexos, H. Béjar, 1988).

La cultura de la acción, que nació como cultura de identidad para agrupar a los trabajadores activos, se ha ido convirtiendo en la marca de un cierto tipo de acción y en generadora de una restricción fundamental a la hora de afiliar trabajadores en el marco de una sociedad industrial avanzada o semiavanzada. Tal autoimagen de la acción funda estereotipos ad hoc, y sobre esos estereotipos (p.e.: Los trabajadores no afiliados no son activos y carecen de conciencia de clase) se genera un guión o script (en el sentido que dan al término Schnak y Abelson (1987) como «un paquete de información que contiene información estereotípica» A. Sandford, 1990: 47) que, en lo que respecta a este estereotipo que estamos viendo relativo a la acción y a la conciencia de clase, podría ser éste (siguiendo el modelo de Sanford, op. cit., p. 48):

Expectativas sobre la afiliación desde la perspectiva estereotípica del afiliado en función de las polaridades activo/pasivo y con/sin conciencia de clase:

Requisitos:

a) El sindicalista desea cambiar el mundo en sus estructuras de clase 0 , al menos, mejorar la relación de fuerzas en favor de los trabajadores, para lo cual debe afiliar al mayor número de éstos a su sindicato.

b) El sindicalista posee un sindicato como instrumento de cambio.

Personajes: sindicalista, sindicable.

Secuencia de acción:

1. El sindicalista busca y encuentra al sindicable (acción). 
2. El sindicalista informa al sindicable de lo que es la conciencia de clase.

3. El sindicalista informa al sindicable sobre su carencia de conciencia de dase por no estar afiliado al sindicato.

4. a) lo convence hacia la afiliación, b) no lo convence. Si b, entonces estamos ante un apático con/sin conciencia de clase, según acepte o no lo sustancial del planteamiento que sele hizo. Si a, entonces:

5. El sindicalista ha engrosado la organización con un nuevo miembro y ha acrecentado la conciencia de clase de los trabajadores.

Un guión similar a éste parece deducirse de las atribuciones dicotómicas que genera la cultura sindical, de tal manera que el conjunto de los trabajadores no afiliados pertenecen a ese género exterior a la acción y a la conciencia (al sindicato), lo cual desencadena una relación crecientemente conflictiva con los trabajadores no sindicados, que tienden, a su vez, crecientemente, a adoptar estrategias instrumentales individuales del tipo free rider o gorrón (VV.AA., « ntereses individuales y acción colectiva», en Zona Abierta, núm. 54-55, 1990; M . O Ison, 1986 (1982), 1971) y a desentenderse de los asuntos colectivos (A. O . H irschman, 1986 (1982)). Y parece cierto que la fragmentación de los intereses sociales en Europa hace cada vez más difícil la acción colectiva de carácter sindical sobre las bases atributivas citadas. El endogrupo sindical establece una frontera muy rígida con el exogrupo y limita sus posibilidades:

No es apenas sorprendente decir que el mejor modo de predecir si una persona albergará actitudes hostiles hacia un grupo particular y cuál será el contenido de esas actitudes, es hallar cómo comprende la situación intergrupal. Y aún resulta menos sorprendente decir que este modo de comprender va a afectar su conducta. Por supuesto, esto no significa que los factores motivacionales y emocionales sean poco importantes, pero también es cierto que la mayor ventaja adaptativa del hombre es su capacidad para modificar su conducta en función del modo como percibe y comprende una situación (H . Tajfel, 1984: 158. Cursivas mías).

Parece cierto que «el problema que se plantea al movimiento sindical y obrero es aceptar una diversidad a la que no está acostumbrado» (Antoniazzi, 1986). Pero si seguimos los razonamientos sobre la acción colectiva de $M$ ancur 0 Ison, el problema de la diversidad (la heterogeneidad social: fragmentación de la clase obrera histórica, dificultades de uso del concepto de clase, etc.) va decididamente en contra de las grandes organizaciones: «U na clientela heterogénea, que mantiene distintas demandas de bienes colectivos, puede plantear un problema aún mayor a las asociaciones privadas, que no sólo deben hacer frente a los desacuerdos, sino también encontrar incentivos selectivos lo bastante fuertes como para retener a los clientes insatiffechos. En pocas palabras: Ios animadores políticos que tratan de organizar la acción colectiva tendrán más posibilidades de éxito si se esfuerzan por reunir grupos relativamente homogéneos» (M. Olson, 1986: 42). Una diversidad que, en todo caso, entraña modificaciones en la definición de la situación, redefinición que no se produce en el colectivo sindical, o que se produce muy lentamente, o que 
se produce en núcleos muy restringidos y no se difunde por diversos motivos, pudiendo mantenerse una definición de la situación variable según diversas estructuras de la organización: estas anomalías o variantes con respecto a una supuesta definición única de la situación (en el sentido kuhniano de anomalía; T. Kuhn, 1971) son probablemente la expresión no sólo de alguna o algunas subculturas organizativas, sino, y sobre todo, de un desdoblamiento entre lo científicamente conocido (el cambio en una situación) y las posibilidades de comunicarlo sin riesgo de crear o acrecentar problemas tales como el de la identidad ideológica (y cultural) del sindicato o el de la propia y supuesta homogeneidad, cuya conversión en problema puede ser, a su vez, un grave problema. La tendencia a plantear las cuestiones en términos dicotómicos (izquierda/derecha; activo/pasivo; con/sin conciencia de clase, etc.) debe obstaculizar el análisis de la situación (y su redefinición) hasta el punto de hacer muy difícil cualquier modificación de cualquier tipo y a ver cualquier innovación en términos de acción negativa del exogrupo sobre el endogrupo. No digamos si alguna de esas innovaciones tiene algo que ver con la cultura o la ideología atribuida al enemigo o adversario. En estas condiciones, la redefinición de la situación y la transformación de las conductas a partir de las modificaciones ideológico-culturales introducidas, es o muy lenta o imposible.

La censura obvia que propició una cierta versión moral del marxismo (que se definió por su fundador como materialismo) sobre los temas de la racionalidad individual y colectiva, hizo prevalecer el esquema genérico intereses de los capi talistaślintereses de los trabajadores como orientador básico de la definición de la situación y generador de modelos de procesos cognitivos fundados sobre esa y otras dicotomías: los temas del cál culo racional y el análisis científico de intereses, así como otras cuestiones básicas que fueron surgiendo en las ciencias sociales, no afectaron a las grandes organizaciones de clase, aunque al gunos intelectuales de raíz marxista (el llamado marxismo analítico, p.e.) recogieran el reto e intentaran retomar estos temas desde una perspectiva interior a la izquierda.

\section{Errores funcionales. Centro y periferia del grupo}

Los trabajos históricos de Solomon Asch sobre conformismo y sumisión en el grupo $(1951,1955,1956,1961)$ y los de M uzafer Sherif sobre las normas en el grupo $(1936,1969)$ son aún hoy una referencia obligada para todo trabajo de investigación básica en el área de las relaciones individuo/organización/cultura. A partir de ahí se desarrolló una línea de investigación persistente en el área de la psicología social y la sociología de grupos. 0 tras tradiciones analíticas, como la que abre, en parte, M ichels (1911) sobre los partidos, continuada por D uverger (1951), o aquélla, de superior entidad metodológica, que arranca de Seymour M . Lipset, Trow y Coleman (U nion D emocracy, 1956), y que llega hasta hoy, anal izando empíricamente las organizaciones de interés, en particular las sindicales. Y aún aquella encuadrable en lo que hoy Ilamamos «sociología de las organizaciones» y que está referida sobre todo a la 
empresa, que, partiendo de Taylor, Fayol, M ayo y otros pioneros, llega hasta hoy confundida con el análisis de gestión. É stas y otras líneas han tenido que afrontar la cuestión de la peculiaridad del grupo frente al individuo, y todo lo que de ello se deriva: autonomía frente a grupalidad, individuo frente a sociedad, comunidad, etc., génesis de normas grupales, cohesión, sumisión, percepción, construcción colectiva de la realidad, etc. Si hubiera que buscar un enunciado común para sintetizar toda esta investigación acumulada, este podría ser muy bien el siguiente: la definición de la situación es una construcción colectiva interactiva que define la significación de las circunstancias inmediatas en los términos que confirman y refuerzan la grupalidad, y así, la construcción de la realidad debe entenderse en términos similares: las definiciones grupales de la situación deben tener un gran papel en la labor colectiva interactiva de percepción o construcción de tal realidad. Pero este acatamiento de la función grupal en el origen y estabilidad de las creencias no es incompatible con la valoración del camino individual (o aparentemente individual, o parcial o totalmente, incluso), pues la racionalidad o irracionalidad del conjunto, si bien no es la suma de sus partes, sí nace de sus componentes: las teorías de la elección social (Arrow y otros) y sus derivados, así como los análisis de la lógica de la acción colectiva (O Ison, Coleman y otros) o la analítica interdisciplinaria sobre la racionalidad (Elster, $\mathrm{H}$ irschman y otros), conforman unos desarrollos que completan la perspectiva estrictamente sociológica, antropológica y psicosociológica.

Y a estas líneas es preciso referirse para situar la cuestión de la construcción cultural colectiva de una organización sindical, como en el caso que ahora nos ocupa, porque este trabajo es interparadigmático y no tiene un referente de tradición única. Al contrario, la posibilidad de ir reduciendo redundancias conceptuales y acercando perspectivas está presente, aún a riesgo de reducir también la claridad que da el operar exclusivamente desde dentro de un sólo sistema categorial.

El concepto de prejuicio que usa Tajfel, citando el texto de Klineberg (1977, EICCSS; H. Tajfel, op. cit., p. 159), incluye una clara diferenciación con el estereotipo, de tal forma que nos permite diferenciar ya cuando estamos ante unos u otros (según se incluya valoración en la imagen previa: un prejuicio sería un estereotipo con valoración, con específicas consecuencias conductuales, como es el caso de los prejuicios de la acción y la conciencia de dase, fundados sobre estereotipos):

El término inglés prejudice y sus equival entes en muchos otros idiomas europeos se refiere principalmente a un juicio previo o a una precomprensión a la que se llega antes de que se recoja o examine la información pertinente y que por lo tanto se basa en razones inadecuadas o incluso imaginarias. En la ciencia social contemporánea esta noción ha sido conservada, pero, por lo general, se considera que constituye sólo un aspecto del fenómeno complejo del prejuicio, a saber, el aspecto conceptual o cognoscitivo - las ideas u opiniones que tenemos acerca de los individuos o grupos que son objeto de tal juicio previo: el término estereotipo se aplica por lo general a este aspecto- . El prejuicio 
implica también una actitud a favor o en contra, la adscripción de un valor positivo 0 negativo, un componente afectivo o sentimental. N ormalmente hay, además, una disposición a expresar los juicios y sentimientos que experimentamos, a comportarnos de una manera que refleja nuestra aceptación o rechazo de los otros: éste es el aspecto conativo, o conductual, del prejuicio (las acciones resultantes pueden ser descritas también según los diversos grados de discriminación que representan). El prejuicio puede, por tanto, definirse como un juicio previo no comprobado, de carácter favorable o desfavorable, acerca de un individuo o de un grupo, tendente a la acción en un sentido congruente (cursivas mías).

Para aclarar y diferenciar estos y otros conceptos introducidos hasta ahora, podríamos hacer el siguiente esquema didáctico:

a) $\mathrm{H}$ ay un proceso de orden que lleva a la categorización del mundo.

b) $\mathrm{H}$ ay, en el proceso categorizador, la necesidad de hacer atribuciones a los otros.

c) Estas atribuciones pueden ser prejui cios o estereoti pos, según se haga o no valoración positiva o negativa del objeto.

Tenemos ya procesual mente definidos los términos más usados, cada uno de los cuales ha dado lugar a una tradición de investigación, de tal manera que a veces, en esas tradiciones no siempre muy vinculadas, parecen incluirse todos estos términos en cada uno de ellos, por mor de la autonomía de cada uno de esos campos, aunque crezca la confusión semántica. Así, tienden a usarse indistintamente conceptos diferenciados.

En el apartado 2 citamos a Elster sobre el tema de las consecuencias de los errores (los errores útiles), y apoyando ahora esa tesis sobre los efectos no perversos de errores en la racionalidad esperada, veremos cómo, efectivamente, desde la perspectiva empírica de la racionalidad de la acción social, podemos decir que los mecanismos autoconservantes que plantean la paradoja de la reminiscencia o regreso o permanencia (en estos sentidos usamos el término reminiscencia) de ideas supuestamente inservibles para la adaptación social de una organización, se apoyan en procesos explicables empíricamente según esta descripción de Tajfel (op. cit., p. 162):

El hombre con prejuicios está comprometido emocionalmente en el mantenimiento de la diferenciación entre su propio grupo y los "otros". A los juicios desacertados no les si guen las consecuencias negativas obvias de los juicios desacertados sobre las propiedades físicas del ambiente. Al contrario, la preservación de estos juicios es autorrecompensante, y esto sucede así sobre todo cuando las estimaciones basadas en prejuicios se hacen en un contexto social que apoya fuertemente las actitudes hostiles respecto a un grupo particular. Por tanto, nos enfrentamos con un efecto de espiral en el que la existencia del prejuicio en general no sólo proporciona apoyo adicional y recompensas para los juicios hostiles, sino que, además, quita la posibilidad de una «prueba de la realidad» de tales juicios, que se alimentan los unos a los otros y se entrelazan cada vez más fuertemente bajo la forma de poderosos mitos sociales (cursivas mías). 
Si a los juicios desacertados no le siguen consecuencias negativas inmediatas (que son las que podían forzar un cambio de opinión, según el material empírico de la teoría del aprendizaje), el modelo de proceso cognitivo del mundo, en particular del mundo sociolaboral propio de un sindicato, incluye reflexiones anómal as más o menos conscientes del tipo «si trato de entender de otra manera la actitud de al gunos trabajadores, disentiré de la mayoría (con las consecuencias que se pueden esperar), por tanto entenderé las cosas de la forma en que las entienden los míos». En todo grupo, la opinión más general dentro de la organización (que se vincula con frecuencia a una moral de las creencias posibles o positivas y que acompaña a la ideología en sentido estricto) parece tender a convertir en estímulos de evitación a las opiniones contrarias o diversas. Un estímulo de evitación, como su nombre explicita, es aquél que, por sus consecuencias negativas (refuerzo negativo), debe ser evitado. Weber (1979: 29) lo dice con estas palabras: «Toda moral con "validez" efectiva - en el sentido de la sociología- suele estar garantizada ampliamente en forma convencional, o sea por la probabilidad de una reprobación de la transgresión».

Esto entra en lo que podemos Ilamar las respuestas de la organización al entorno (A. Panebianco, 1990: 337 y s.), y está fundado en unos presupuestos teóricos que tienden, crecientemente, a matizar el determinismo en las ciencias sociales (y el de las teorías estrictas de la contingencia en la sociol ogía de las organizaciones) y a entender tanto a los sujetos individuales o colectivos como verdaderos sujetos, capaces no sólo de ser influidos por el entorno, sino de responder a él activamente (A. Panebianco, op. cit., p. 10; F. Bouza, 1984). En este sentido, los estímulos hacia la adaptación a nuevas circunstancias de cualquier índole (adaptación al entorno) no sólo encuentran la respuesta, digamos automática, de la inercia cultural hacia la conservación de toda organización, sino también la respuesta racional (en sentido no valorativo 0 absoluto de la palabra) de sus componentes, tanto agrupados en diversas estructuras como individualizados, hacia la supuestamente necesaria adaptación o hacia la resistencia a ella, según un cálculo cognitivo complejo cuyos exactos pasos desconocemos.

Cuanto más próximos a la adopción de decisiones organizativas mayor es la tendencia de los afiliados y delegados a culpar de la crisis sindical al mundo externo (desinterés de los trabajadores) y menor a culpar de ella al propio sindicato (mal funcionamiento delos sindicatos) (tabla 1, F. Bouza, 1990c).

Tabla 1. Respuesta sobre la principal responsabilidad de la crisis de afiliación sindical.

D elegados afiliados

Afiliados*

D elegados no afiliados

D elegados ex afiliados

\begin{tabular}{lll} 
D esinterés & M al funcionamiento & Encuestados \\
\hline $75 \%$ & $20 \%$ & 422 \\
\hline $64 \%$ & $29 \%$ & 374 \\
\hline $59 \%$ & $32 \%$ & 142 \\
\hline $55 \%$ & $41 \%$ & 31
\end{tabular}

* Afiliados que no son ni fueron nunca delegados: «afiliados base», distinto a «afiliados muestra» (todos, delegados o no, que entraron en la muestra de afiliados). 
Tanto los delegados por U GT que no pertenecen al sindicato (figura posible y frecuente) como aquellos delegados que se han dado de baja en el sindicato tienen unos porcentajes de imputación negativa al trabajador no afiliado menores. Los delegados afiliados, verdadero motor del sindicato, tienen el más alto porcentaje de imputación negativa.

Podemos observar aquí (igual que ocurre en la percepción por adjetivos del trabajador no afiliado, en donde los afiliados, delegados o no, incluían como adjetivo más elegido el de apático, y después el de sin conciencia de clase - en el caso de los afiliados base o sin cargo ni ayer ni hoy la atribución sin ideología aparecía un punto directo o de enunciación sobre sin conciencia de clase- ) como los no afiliados (que entonces ponían en primer lugar el adjetivo inde pendiente) tienen una actitud crítica más matizada hacia el exogrupo, al que en cierto modo también pertenecen en su función bicéfala de delegados no afiliados.

D e esta forma podemos observar la expansión en big-bang de la cultura y de la ideología de la organización, con sus diversas atribuciones (prejuicios y este reotipos). Y es en esa periferia cultural en donde se hace más débil la cohesión 0 la conformidad.

Las investigaciones sobre las relaciones entre tamaño del grupo y cohesión u homogeneidad ideológica son insuficientes y ambiguas: no hay datos claros que permitan hacer afirmaciones sobre esto:

Estas observaciones de carácter intuitivo sobre el papel que tiene el tamaño (se refiere el autor a Van D oorn - Conflict in Formal O rganization- , Sjöblon - Party Strategies in M ultiparty System- y K ircheimer - Politics, Law and Social Change : todos establecen alguna relación entre tamaño y cohesión) vienen a establecer una serie de relaciones de este tipo: dimensiones reducidas igual a elevada homogeneidad política interna y, por consiguiente, grupo dirigente unido; grandes dimensiones igual a el evada heterogeneidad política y, por consiguiente, grupo dirigente dividido. Son observaciones intuitivas pero no del todo satisfactorias (A. Panebianco, op. cit. p., 345).

Efectivamente, la fundamentación empírica de una relación de este tipo tropi eza con la dificultad o la imposibilidad de manejar grupos grandes en situaciones de laboratorio y, por tanto, de remitir el problema a los cuasi experimentos, con observaciones ex post, o a la observación participante, con sus limitaciones. Además, la infinidad de variables que confluyen en una cuestión de este tipo dificultan enormemente la posibilidad de generar enunciados de base empírica suficientemente significativos que vinculen cohesión y tamaño. Los trabajos clásicos de Asch, y las réplicas de G erard y otros (1968), no pueden extrapolarse a grandes grupos.

M ancur O Ison analiza la relación tamaño/eficacia desde la perspectiva dicotómica pequeños/grandes grupos, nunca suficientemente definidos en sus textos. Aún aś, sus observaciones son muy pertinentes para analizar los problemas de los grandes sindicatos históricos de clase: 
[... ] cuanto mayor sea la cantidad de individuos o empresas que se beneficien de un bien colectivo, menor será el porcentaje de ganancias obtenidas a través de la acción en favor del grupo que le va a corresponder al individuo o empresa que lleva a cabo la acción. Así, en caso de no existir incentivos sel ectivos, el incentivo de la acción de grupo disminuye a medida que aumenta el tamaño del grupo, de modo que los grandes grupos están menos capacitados que los pequeños para actuar en favor de un interés común (M . O Ison, op. cit., p. 50).

Algunas cuestiones parecen propias (aunque no esencial o necesariamente propias) de los grandes grupos, como un sindicato o un partido. Temas como la distribución jerárquicamente decreciente de la información y, por tanto, de la cultura y la ideología del grupo aparecen claras en los índices usados por nosotros en esas encuestas interiores. Además de la tabla de imputaciones por la no afiliación y la de los adjetivos, podemos añadir, entre otras muchas pruebas de esto, los datos de las tablas 2 a 5 :

Tabla 2. Satisfacción hacia la información recibida sobre lo que ocurre y se decide en UGT.

\begin{tabular}{|c|c|c|}
\hline & $\begin{array}{l}\text { D elegados } \\
\text { (estén o no afiliados) }\end{array}$ & Afiliados \\
\hline $\begin{array}{l}\text { e siente «poco o nada» informado } \\
\text { obre lo que ocurre en la U G T }\end{array}$ & $62 \%(592)$ & $72 \%(521)$ \\
\hline
\end{tabular}

Si desglosamos la categoría «delegado» en sus tres componentes (delegados afiliados, delegados no afiliados y del egados ex afiliados):

Tabla 3.

D elegados afiliados

no afiliados ex afiliados

Se siente «poco o nada» informado sobre lo que ocurre en la U GT

$55 \%(422) \quad 78 \%(138) \quad 78 \%(32)$

0 bien, objetivizando la pregunta hacia la información recibida:

Tabla 4. Recepción de boletines diversos..

\begin{tabular}{lcc}
\hline $\begin{array}{l}\text { Procedencia } \\
\text { o editor }\end{array}$ & $\begin{array}{c}\text { D elegados } \\
\text { (estén o no afiliados) }\end{array}$ & $\begin{array}{c}\text { Afiliados } \\
\text { (muestra) }\end{array}$ \\
\hline Unión territorial & $3 \%$ & $3 \%$ \\
Federación de industria & $10 \%$ & $5 \%$ \\
Comisión ejecutiva confederal (U nión) & $62 \%$ & $30 \%$ \\
O tros & $9 \%$ & $4 \%$ \\
N S/N C & $5 \%$ & $2 \%$ \\
\hline Total encuestados & $\mathbf{5 8 8}$ & $\mathbf{5 2 0}$ \\
\hline
\end{tabular}


Y desglosando la categoría «delegado» en sus tres modos (afiliado, no afiliado y ex afiliado):

Tabla 5.

\begin{tabular}{llll}
\hline & $\begin{array}{l}\text { D elegados } \\
\text { afiliados }\end{array}$ & no afiliados & ex afiliados \\
\cline { 2 - 4 } & $9 \%(46)$ & $19 \%(28)$ & $23 \%(7)$ \\
\hline
\end{tabular}

La cantidad jerárquicamente decreciente de información subraya la existencia de lo que podríamos llamar una «depresión periférica» del sindicato que ofrece en sus bordes jerárquicos los flancos más débiles culturalmente (me refiero a la cultura-ideología), y aquéllos, por tanto, más asequibles a una recepción menos vinculada a la cultura nuclear de la organización, aunque la misma probable variedad de esta afiliación desinformada y periférica haga impensable una agrupación conceptual del tipo «os más x 0 y» (los más desinformados, sin duda) relativa a aspectos culturales-ideológicos: los más modernos, combativos, pasivos, activos, etc.

En el conjunto de informes y artículos (F. Bouza, informes y artículos citados en la bibliografía) pueden observarse muchas otras tablas que explicitan esa depresión informativa y, en general, esa distancia entre el núcleo y la periferia, propia de una organización que ha tenido que asimilar en el postfranquismo una importante cantidad de afiliación nueva y que se convirtió, casi de la noche a la mañana, en una organización compleja, con déficits notables de todo tipo.

$\mathrm{H}$ ay elementos discursivos en la opinión recogida entre los afiliados a U GT que parecen expresar una realidad mucho más radical que la imagen que da el sindicato, situado en una línea histórica socialista de corte socialdemócrata, en el sentido moderado que tenía ese adjetivo en el medio político de izquierdas. Parecen supervivencias funcionales de una definición colectiva de la situación que fue más correcta que lo que hoy es. Pero aquello que sobrevive no lo hace por raras cuestiones metafísicas, sino porque hay al go en la situación que contribuye a ello: y estamos otra vez en el tema de los errores útiles. $\mathrm{iH}$ ay realmente una racionalidad eficaz en el mantenimiento de las definiciones, oposiciones y adjetivos de la cultura sindical histórica?

No se puede olvidar, para comprender algún sentido de este trabajo, que ha sido el propio sindicato el que encargó las investigaciones, en un intento de conocer su propia situación y la de la afiliación en general: no estamos, pues, ante una crítica exterior, sino ante la propia acción racional de la organización en busca de sus déficits.

\section{Acción colectiva, interés, reminiscencia e identidad}

Las trabajos de $M$ ancur O Ison $(1965,1986)$ han introducido una forma relativamente nueva de analizar los procesos sindicales en términos de interés y 
racionalidad, en línea con la tradición de elección social y de la conceptuación económico-utilitaria. Al fondo de este tipo de tradiciones aparece el dilema del prisionero, que la teoría de juegos (M . D . D avis, 1971: 108 y s.) actualiza para su uso como ejemplo de la contradicción acción individual/acción colectiva (intereses individuales/intereses colectivos): es posible una solución óptima cooperativa frente al albur de la acción individual. Bien, la cuestión es darle contenido real a lo que no es más que un esquema lógico: en qué condiciones las soluciones cooperativas son mejores que las individuales, y qué clase de cooperación es la precisa para cada caso, y en qué medida un sindicato representa una lógica cooperativa eficaz en las condiciones sociales actuales del mundo industrial?

Las tesis de O Ison se elaboran contra la concepción habitual (marxista, según O Ison, de sentido común, diría yo):

De modo general, si los individuos de determinada categoría o clase social tuviesen un grado suficiente de interés propio, y si todos ellos coincidiesen en un interés compartido, el grupo actuaría asimismo de una manera favorable a sus propios intereses. Si examinamos con cuidado la lógica de la frecuente suposición que se recoge en el párrafo anterior, cabe apreciar que es básica e indiscutiblemente errónea... [pero] dado que cualquier ganancia se aplica a todos los miembros del grupo, aquéllos que no contribuyen para nada al esfuerzo conseguirán tanto como los que efectuaron su aportación personal. Vale la pena «dejar que lo haga otro», pero el otro tampoco tiene demasiados incentivos - si es que tiene alguno- para actuar en favor del grupo. Por lo tanto, en ausencia de factores que ignoren por completo las concepciones mencionadas en el primer párrafo de este capítulo, habrá una muy escasa acción de grupo, en el caso hipotético de que la haya. En tal eventualidad, la paradoja consiste en que - s no se dan combinaciones o circunstancias especiales, sobre las que volveremos más adelante- los grandes grupos, por lo menos si están compuestos de individuos racionales, no actuarán en favor de sus intereses de grupo (M. OIson, 1986: 32-33).

Este tipo de análisis fundado en la racionalidad instrumental del hombre económico difícilmente pueden dar cuenta de los vericuetos de una racionalidad tan compleja como la que podría operar en sindicalismos históricos de origen marxista 0 anarquista sustentados en una cultura moral católica comunitaria y culpabilizadora. Con todo, a medida que el tipo de moral de fondo se va transformando, el «altruismo egoísta» o el «egoísmo racional» podrían ser una alternativa al egoísmo a secas que los segmentos diferenciados de trabajadores van aplicando a su política sindical en un momento en que la dificultad de los grandes sindicatos para controlar al conjunto del movimiento sindical hace que aparezcan multitud de pequeñas agrupaciones con alternativas muy limitadas. Entre el racionalismo instrumental de estos trabajadores y el «racionalismo» tradicional de los sindicatos fundado en una definición de la situación que es continuista con respecto al sindicalismo histórico (dos bloques - capital, trabaj0- , dos intereses - capitalistas, trabajadores- : «La clase trabajadora organizada declara que la forma de producción actual se caracteriza por 
Tabla 6. Diversas oposiciones restrictivas que aparecen en el cualitativo (once grupos de discusión de diversa composición).

\begin{tabular}{ll}
\hline Afiliado & No afiliado o afiliado no activo \\
\hline $\begin{array}{l}\text { Sección Sindical } \\
\text { Desinterés (conducta }\end{array}$ & $\begin{array}{l}\text { Comité de Empresa. Asambleas } \\
\text { Interés (conducta interesada o egoísta): } \\
\text { sentimentala): } \text { «romántico, } \\
\text { Conciencia (de clase, idealista» }\end{array}$ \\
«materialista»
\end{tabular}

la existencia de dos categorías o agrupaciones de clase: capitalistas (dueños o poseedores de los instrumentos de trabajo y usufructuarios de los modos de producción) y trabajadores (asalariados que crean en condiciones inferiores - económicas, políticas y jurídicas- la riqueza colectiva o social». D el U GT. M anual del afiliado), no hay casi nada en común. He aquí el sistema completo de oposiciones que los trabajadores sindicados daban en el cualitativo (tabla 6, F. Bouza, 1990c).

A modo de contrapunto, los no afiliados (en sus grupos de discusión) cal ificaron a los sindicatos de no representativos, sin credibilidad, cerrados, masificadores, oscuros, grises, lúgubres, partidistas, traicioneros, clasistas, destructivos, anticuados, reventadores.

Para satisfacción de 0 Ison, al gún no afiliado resume así su relación con los sindicatos: les das tú mása ellos de lo quete dan a ti. Una racionalidad implacable que quizá sea extensiva a muchos otros trabajadores. La traducción en términos olsonianos sería: afiliándote les das tú más a ellos que ellos a ti, sobre todo porque si no te afilias recibes lo mi smo sin dar nada: ni cuotas, ni reuniones, etc. $\mathrm{N}$ i siquiera los servicios de un sindicato parecen resultar muy atractivos si es a costa de la militancia, y sólo a veces, de forma puramente oportunista, al guien confiesa haber entrado en el sindicato para obtener al gún servicio y darse luego de baja.

Todo parece apuntar a las tesis de O Ison en favor de la prevalencia de los pequeños grupos:

Cuando el grupo está compuesto sólo de unos cuantos miembros, también aparece la posibilidad de que negocien entre sí y acuerden una determinada acción colectiva. En tal caso, la acción de cada uno posee un efecto perceptible sobre los intereses y sobre el curso de acción que sigan los demás, de mane ra que todos tienen un incentivo para actuar estratégicamente, es decir, de una forma que tome en cuenta el efecto de las opciones individuales sobre las opciones de los demás. Esta interdependencia entre las distintas empresas o personas que constituyen el grupo puede otorgarles un incentivo para negociar mutuamente en beneficio recíproco. En realidad, si los costos de la negocia- 
ción son escasos, tendrán el incentivo de continuar negociando entre sí hasta que se maximicen las ganancias del grupo, es decir, hasta lograr lo que llamaremos un resultado óptimo de grupo (o lo que los economistas denominan a veces un «óptimo de Pareto» para el grupo) (M . O Ison, op. cit., p. 48).

Sin embargo, Albert 0 . H irschman en su Interés privado y acción pública (1986: 90) hace una revisión de las tesis de 0 Ison bajo una perspectiva particularmente interesante para nosotros, que estamos observando a un sindicato histórico de clase: «U na crítica general que puede formularse contra el análisis de $\mathrm{O}$ Ison - y contra gran parte de la teoría de la decisión económica en general- es el hecho de que sus agentes, si bien son eficientes y a menudo aun ingeniosos y astutos, carecen de historia». H irschman introduce la variable «historia» (que en sus planteamientos entiendo yo que equivale a la variable «aprendizaje» 0 «memoria», incluso «memoria colectiva») como un elemento que modifica aspectos de las conductas racionales obvias y ahistóricas (H irschman está defendiendo ciclos del tipo privado/público de causación mutua, que entrañan historia y memoria social). Por otra parte, no hay cognición sin historia (J. Lave, 1991), ni racionalidad que no la incluya, salvo que trabajemos como modelos ideal es galileanos. En este sentido, pero aplicado al tema de la acción sindical colectiva y pública traemos aquí el concepto-variable historia. Y lo hacemos para relativizar las tesis de 0 Ison (él las resume así: «La tesis expuesta en este capítulo predice que aquellos grupos que tengan acceso a incentivos selectivos probablemente actuarán de manera colectiva para obtener bienes colectivos con más frecuencia que los grupos que no disponen de tales incentivos. Además, es más probable que los grupos más reducidos emprendan una acción colectiva, en comparación con los grupos más numerosos, op. cit., p. 54). La historia del sindicalismo español nos muestra una acción esencialmente ideológica y política, y la racionalidad histórica de estas organiza ciones está fuertemente determinada por la extraña mezcla de ideología revolucionaria (anarquista, socialista, comunista) y cultura religiosa (un fuerte comunalismo organizativo, una cultura de salvación colectiva, una moral estricta y puritana, un sentido de la acción muy evangélico - la fe sin obras es fe muerta- y un cierto y paradójico desprecio hacia lo económico). El resultado histórico son unos sindicatos muy enfrentados con el Estado y más vencidos hacia los incentivos col ectivos que hacia los incentivos sel ectivos. El historiador Santos J uliá (1990: 55) lo resume ( «La permanencia entre los obreros españoles de una común expectativa y práctica revolucionaria puede relacionarse con el superior, pero siempre vulnerable, crecimiento sindical hasta 1930 y con la ausencia de fuertes partidos políticos obreros en la España de la segunda mitad de la Restauración. Estos fenómenos explicarían, por una parte, la diferencia entre los movimientos obreros europeos y el español, que no radicaría tanto en la permanencia del anarcosindicalismo como en el predominio de los sindicatos sobre los partidos políticos, y, por otra, la ausencia de un proceso de incorporación obrera a los mecanismos políticos parlamentarios. Los trabajadores españoles - tanto en la CN T como en la U GT - se caracterizaban por 
su indiferencia hacia la forma política del Estado y por su hostilidad ante el poder político, lo que naturalmente dio lugar a la ausencia de debate sobre el Estado y la conquista del poder - aquí no hubo realmente discusión entre socialdemócratas y bolcheviques - y a la creencia de que el contenido político de la revolución era sencillamente la administración de la sociedad por las organizaciones obreras. Loa socialistas, que se presentaban a pesar de todo a las elecciones, llegaban a rechazar como calumnioso el propósito que se les atribuía de conseguir la mayoría parlamentaria. Su presencia en el Parlamento no tenía más objeto que el de hacer allí de "voceros" de las organizaciones obreras, o sea, de los sindicatos») centrando la cuestión en la tendencia política de los sindicatos a suplantar a los mismos partidos, y, sin embargo, para conceptuar este proceso la expresión antipolítica es más ajustada, en mi criterio. El marco de todo ello es la peculiaridad de la situación española, que resume así Carlos M oya:

El paso de la vieja sociedad estamental a la moderna sociedad industrial de clases tiene un desarrollo singularmente traumático en nuestro país. La Constitución liberal de las C ortes de Cádiz, con su valor carismático acuñado en una guerra de liberación nacional, al trascender utópicamente el desastre económico-social que resulta de aquella guerra, dispara la dramática paradoja que inaugura y preside la historia política del siglo XIX español: un modelo liberal para una sociedad sin clase nacional burguesa; un sistema «moderno» de fórmulas ideológicas y organizativas para una estructura social que hace imposible su vigencia en cuanto esa práctica realidad colectiva constituye la negación radical de aquel proyecto político. M anteniéndose esa paradoja histórica a lo largo de todo el siglo, determinará su condición «pintoresca o fastidiosa» (Pierre Vilar) - y a la vez trágica - de aquel desarrollo. Se trata de un país que liquida los restos de un imperio enorme, precapitalista, sin conseguir al canzar el nivel correspondiente a una potencia nacional moderna; carece para ello del requisito político-organizativo necesario: un Estado nacional mínimamente moderno y racional, en cuyo marco se desarrolle paulatinamente un mercado y una clase nacional burguesa.

A su vez, estas desviaciones estructurales sobre el modelo normal de modernización, conformaron un fuerte sindicalismo popular, que aglutinó a su alrededor todas las esperanzas revolucionarias.

Por eso, el actual tema de la insuficiencia de afiliación a los sindicatos puede entenderse también como un conflicto de identidad: se trata de sustituir una cultura de lo colectivo por otra de lo sel ectivo o de lo colectivo-sel ectivo, y esto es mucho más que la introducción de algunos servicios para los afiliados: es toda una cultura-ideología que ha nutrido la tradición sindical de definiciones de situación y de construcciones comunes de la realidad.

En tanto que coalición de distribución, un sindicato (al margen de otras consideraciones, como tamaño o eficacia afiliativa) caería en el ámbito de la crítica de $\mathrm{M}$ ancur O Ison (op. cit., p. 103-1.045) de frenar la producción y orientar la dinámica social hacia la distribución. Es una perspectiva a tener en cuenta, pero es demasiado obvia para explicar la complejidad de tales socie- 
dades: al contrario, todo parece indicar que allí donde existen sindicatos estables la economía es más adaptativa. Al menos hasta ahora ha sido así.

En todo caso, la permanencia o regreso, paradójicamente, de culturas tradicionales en el sindicato (paradojas de la reminiscencia) cuando acucia más un cambio cultural, parece tener como principal objetivo la salvaguarda de la identidad y de las fronteras, una manera de responder al desorden externo en el terreno de las ideas y de la estructura social. En condiciones de transformación rápida del mundo, y a falta de una estructura partidaria interior que pudie ra proponer alternativas de forma organizada, como de las que hablan Lipset, Trow y Coleman (1989: 534), la respuesta parece ser la permanencia cultural.

Aunque estamos hablando de una cultura sindical en declive, esto no tiene un equivalente automático en una acción homogénea de tipo tradicional. A pesar de su cultura histórica y de un cierto radicalismo verbal, lo cierto es que los sindicatos de clase (no sólo U GT) tienden crecientemente a una conducta moderada y razonable, aunque discutible, y no estamos ante grupos revolucionarios ni mucho menos. Esto establece una fractura entre la culturaideología del sindicato y su acción diaria: una cultura dicotómica para una práctica extremadamente reformista, por más que en ocasiones pueda parecer radical vista contra el fondo de una situación política y económica tan espe cial como la española de hoy. La propia dinámica de acuerdos propicia la dificultad de un debate:

[... ] el sindicalismo de negociación económica que se configura como un conjunto de ideas que tienden a justificar las definiciones más limitativas del papel del sindicalismo en la sociedad, contribuye a la legitimación de la oligarquía de un sólo partido, porque implica que el liderazgo consiste senciIlamente en la administración de una organización que persigue unas finalidades incuestionables: la maximización de los ingresos de sus miembros y el bienestar general. Cuanto más limitadamente define sus funciones una organización, concibiéndolas como el cumplimiento de necesidades acotadas y específicas, más estrecho es el margen para la controversia (Lipset, Trow y Coleman, op. cit., p. 537).

El sindicalismo de clase ha unido su suerte a la del socialismo, en unos casos, y a la del comunismo, en otros, y resulta obvio que no pueden los sindicatos eludir su parte en el éxito o la crisis de sus modelos políticos, y parece cierto que los sindicatos deben implicarse más activamente en este debate sobre el futuro del socialismo, lo que no quiere decir implicación partidaria, necesariamente. A las dificultades citadas se añade hoy el cuestionamiento general de un sistema político de igualación sin mercado, modelo común a la izquierda histórica: abordar este tema es también revisar la cultura-ideología tradicional, la definición de la realidad y todo lo que de ahí se deriva.

Esta realidad bicéfala de un sindicalismo pragmático en la negociación y tradicional en la cultura ideológica es quizá la causa de que, efectivamente, estemos más ante sindicatos de representación que de afiliación (L. Paramio, 1990; V. Pérez D íaz, 1987), pues los mi smos trabajadores que se sienten repre 
sentados en la negociación por los sindicatos se sienten muy alejados de su cultura y de su ideol ogía. La crisis de afiliación sería así, en parte, una crisis de historización, por decirlo en términos de un filólogo y semiótico (Cesare Segre, 1981: 33), que expresa con este término, en el territorio de la interpretación literaria, lo que sigue:

[... ] la línea que une a emisor y receptor es una línea histórica. Si el lector es contemporáneo del escritor, su interpretación pone en evidencia en el texto los signos más sobresalientes de su pertenencia a una época, en ausencia de la cual carecería de sentido. Si el lector pertenece a otra época, se da pronto cuenta de que posee una «competencia» diferente a la del escritor; deberá ejecutar, como el crítico, y si hace falta ayudado por el crítico, una serie de maniobras de sintonización y de control que implican un modelo de historización.

Así, un modelo interpretador de esa clase sería aquél que hiciese inteligible para un trabajador medio la cultura y la ideología de los sindicatos de clase en la actualidad: una interpretación, sin la cual un sindicato así carece de sentido. Pero esa interpretación no dejaría de ser sólo un acto interior al tiempo y a la cultura del sindicato, que si bien podría hacerse entender en esas coordenadas espaciotemporales de su historia, no podría justificar la permanencia (la reminiscencia) de su cultura histórica. La imputación a la falta de sindicalismo libre durante el franquismo (L. Paramio, op. cit.), con ser cierta, no da cuenta completa de la persistencia en la no afiliación. Como tampoco la da, en la misma línea, «la desmovilización, la escasa participación y el recelo frente a las organizaciones» (J. M. M aravall, 1981: 184) generadas durante el franquismo: es en el interior de la propia cultura/ideología de los sindicatos donde está la causa central de su expansión limitada, causa que se hace más operativa, ciertamente, en el marco del posfranquismo, con las secuelas citadas por $M$ aravall y Paramio. Probablemente ha sido también ese problema central, unido a las carencias estructurales, con la amenaza de caos interior, lo que limitó la respuesta sindical a las demandas de afiliación. La unión de una cultura tradicional y una organización débil fue lo que no hizo posible el encuadramiento de los trabajadores que acudieron a los sindicatos tras la legal ización (véase el tratamiento que da Panebianco a temas similares - op. cit., cap. 10-). Tampoco el legado de cuatro décadas autoritarias, la crisis económica, la falta de líderes de empresa, los free rider y la oposición patronal a los sindicatos (R. M . Fishman, 1990: 249 y s.) explican las carencias afiliativas, aunque aportan elementos todos ellos significativos. C on todo, si hubiera existido un ajuste mayor entre la cultura sindical y las expectativas de los trabajadores, los sindicatos de clase hubieran desarrollado más rápidamente una afiliación muy superior a la actual.

Ida Regalia (1988), citando sus experiencias y al gunos trabajos de Pizzorno, da una especial relevancia a ciertas variables individual es (complejos procesos de definición del yo en el mundo actual) junto con las colectivas (fisonomía del sindicato en un determinado momento) para explicar la participación 0 no en el movimiento sindical. Por otra parte, la transformación en los mode- 
los de participación (del modelo organizativo-ideológico de pertenencia «sobre bases ideológicas opuestas» al modelo de las movilizaciones, y de éste al de la participación limitada y especializada y no totalizadora y genérica - I. Regalia, op. cit., cap. 6- ) obliga a los sindicatos a dar mayor información a sus afiliados o simpatizantes y a no fundar la acción sólo sobre asambleas multitudinarias, en creciente declive.

Tanto las variables individuales (más importantes si cabe en una sociedad de individuos algo más autónomos) como aquellas variables «técnicas» derivadas de una concepción conflictiva tradicional, como la movilización y la asamblea, requieren un tratamiento específico.

En estas condiciones de dificultad para mantener las identidades históricas, resulta chocante pero explicable la permanencia o la reminiscencia de la cultura tradicional, aún a costa de limitar creciente y peligrosamente la expansión afiliativa.

\section{La opinión interior como proceso colectivo}

Volvamos ahora a la cuestión del ordenamiento del mundo desde el conjunto de categorías aplicadas para ello (ver tabla 6), recordando el mecanismo de reducción de complejidad que esto significa: es, sobre todo, un acto de economía cognitiva. Las experiencias sobre categorización, estereotipos y prejuicios (Tajfel, op. cit.; Potter y Wetherell, op. cit.) muestran unanimidad en cuanto al fenómeno de categorización como tendencia a clasificar el mundo en categorías de agrupamientos según ciertas características con frecuencia infundadas. Para algunos, la categorización prepara el camino del prejuicio (p.e. D. A. W ilder, 1986), pero otros sugieren que «predisposiciones (sesgos) y estereotipos no son aberraciones sociales y psicológicas inducidas por una educación deficiente o por procesos ideológicos distorsionados, sino un ine vitable producto del modo en que nuestro sistema cognitivo está organizado para responder a categorías» (Potter y Wetherell, op. cit., p. 118). A su vez, las categorías funcionan sobre prototipos (Cantor y M ischel, 1977, 1979; Rosch y otros, 1976; Potter y Wetherell, cap. 6): un prototipo es un ejemplo típico 0 paradigmático (Potter y Wetherell, op. cit., p. 119) de algo, tal como usamos la palabra en el lenguaje cotidiano en español: ciertas concomitancias con el prototipo nos lleva a incluir a persona o cosa en la categoría que representa el prototipo o prototipos, que parecen estar jerárquicamente dispuestos en nuestras estrategias cognitivas con diversas ramificaciones específicas: el mundo está ordenado en esta clase de cadenas cognitivas. Así, clasificamos a al guien en la categoría sin conciencia de clase porque se parece al prototipo (un esquema o una imagen concreta realizado/a sobre experiencias previas culturalmente determinadas), y dentro del prototipo en al guna de sus variantes (subprototipos), pasivo p.e, tal como aparece en el discurso sindical el trabajador no sindicado. «EI fenómeno social del estereotipo (estereotipificación) está causado por el modo en que nuestro sistema cognitivo opera sobre la información, reduciendo y distorsionando a la luz de las estructuras organizadas de proto- 
tipos», según sintetizan Potter y Wetherell - op. cit., p. 121- (para matizarla o negarla) la tradición analítica sobre el tema. Para ellos, las personas «en lugar de ser unas "víctimas" de los procesos de categorización mecánica, operarán con flexibilidad sobre las categorías previas y construirán su sentido a medida que hablen» (ibídem), siguiendo el modelo de Billig $(1985,1987)$ y llevando el análisis categorial hacia el análisis retórico más que hacia el perceptivo, como van Dijk $(1983,1984,1985)$ y otros. Yo mismo he buscado por vía retórica la función de ciertas categorizaciones (F. Bouza, 1983, 1984) en el discurso publicitario.

La discusión no afecta al núcleo central del uso que aquí hacemos de esas categorías: decimos que, más o menos flexibles, más o menos determinados, los procesos categorizadores simplifican y economizan nuestras operaciones cognitivas y nos conducen (quizá no necesariamente) al prejuicio y a la fijación del mundo en categorías estables (no necesariamente, tampoco), con lo cual nuestra cultura individual y grupal se cierra al rededor de estas categorizaciones, cuyo cambio no es imposible, pero sí difícil o muy problemático, como muestra la historia humana, que también muestra, efectivamente, cómo grupos determinados han ido transformando sus categorizaciones y sobreviviendo a las modificaciones del mundo: Ia I glesia católica, p.e, en perspectiva histórica, ha ido modificando su relación con la realidad de forma acusada, aún manteniendo un núcleo dogmático básico: puede ser el ejemplo de la sobrevivencia de una organización con cultura tradicional no demasiado modificada y un cierto pragmatismo cotidiano, algo muy parecido a los sindicatos, salvando el objetivo espiritual de la I glesia.

D ebe ser cierto, obviamente, que no hay un determinismo estricto y las personas pueden variar sus esquemas cognitivos: sería terrible que no fuera así y que tuviéramos que convivir toda la vida con los mismos clichés, por más que así ocurra con frecuencia.

A modo de conclusión provisional, podemos decir que la definición de la stuación en el interior del sindicato es un hecho colectivo, que tiene, sin embargo, un núcleo más activo en los sectores más próximos al centro (cargos sindicales y delegados afiliados), que esa definición se hace desde unos hábitos cognitivos históricos enmarcados en toda una cultura sindical que toma la forma de ideología (postulados sistemáticos) en los escritos de la organización. Los procesos de categorización (ver tabla 6) se hacen desde esa cultura-ideología, y aunque pueden ser variables, en este caso parecen bastante constantes. Esta categorización genera una opi nión pública interior a la organización, que tiene aspectos críticos hacia ella, pero que, mayoritariamente, responde a esa cultura.

Cambiar o no esa cultura es un vasto problema estratégico cuyo alcance desborda nuestro ámbito analítico. La retórica de la organización, tal como se muestra en las categorías centrales de la tabla 6, está fundada sobre oposiciones didácticas. La permanencia o regreso de la cultura tradicional en los momentos críticos es una paradoja que nosotros hemos llamado de la reminiscencia. 


\section{Bibliografía}

Abelson, R.P. (1973). «T he Structure of Belief Sistems». En SCH NAK, R.C.; C OLbY, K.M. (eds.). Computer M odels of T hought and Language. San Francisco: W.H. Freeman.

AllPo RT, G. (1954). La naturaleza del prejuicio. Buenos Aires: Eudeba (1971).

AnTONIAZZI, S. (1986). Repensar el sindicalismo. M adrid: H oac.

AREN DT, H . (1958). TheH uman Condition. Chicago: University of Chicago Press.

AsCH , S.(1951). «Effets of group pressure on the modification and distortion of judgments». En GueTZKow, H. (ed.). Groups, leadership and men. Pittsburgh: Carnegie.

- (1955). «0 pinions and social pressure». Scientific American, 193, p. 31-35.

- (1956). «Studies of independence and conformity: A minority of one against an unanimous majority». Psychological M onographs, 70.

- (1961). «ssues in the study of social influence on judgment». En BERG, I.A.; BAsS, B.M . (eds.). Conformity and deviation. Nueva York: $\mathrm{H}$ arper \& Brothers, p. 143-158.

BÉJAR, H . (1988). El ámbito íntimo. Privacidad, individualismo y modernidad, M adrid: Alianza.

BILLIG, M . (1985). «Prejudice, Categorization and Particularization: From a Perceptual to a Rhetorical Approach». European Journal of Social Psychology, 15, p. 79-103.

- (1987). Arguing and Thinking: A Rhetorical Approach to Sodial Psychology. Cambridge: Cambridge University Press.

BouzA, F. (1983). Procedimientos retóricos del cartel. M adrid: CIS.

- (1984). «El sistema simbólico del sentido común». Sociología Contemporánea. O cho temas a debate. M adrid: CIS-Siglo XXI.

- (1990a). «Encuestas» e «nformes» sobre elecciones sindicales y congreso de U GT, $M$ adrid: Fundación Largo C aballero (mimeografía).

- (1990b). «nforme sociológico para la Comisión Ejecutiva Confederal de la UGT sobre la influencia del orden de celebración de elecciones sindicales en los resultados que se produzcan» (mimeografiado, U GT-CEC).

- (1990c). «Actitudes de los trabajadores madrileños hacia los sindicatos». Economía y Sociedad, 3. M adrid.

Bouza, F.; Vargas, M.T.; Asenjo, A.; Borges, F. (1989). Perfil, actitudes y demandas de los trabajadores hacia los sindicatos. M adrid: Fundación Largo C aballero, (edición mimeografiada y síntesis impresa 1989b).

CANTOR, N .; M ISCHEL, W. (1977). «Traits as Prototypes: Effects on Recognition M emory». En Berkowitz, L. (ed.). Advances in Experimental Social Psychology, vol. 9. Londres: Academic Press.

- (1979). «Prototypes in Person Perception». Advances in Experimental Social Psychology, L. Berkowitz (ed.). Vol. 12. Londres: Academic Press.

CIRLOT, J.E. (1978). Diccionario de símbolos. Barcelona: Labor.

CoLEM AN , J.S. (1986). Individual interests and collective action. Cambridge: C ambridge U niversity Press.

D AvIS, M .D. (1971). Teoría del juego. M adrid: Alianza.

D UVERGER, M . (1951). Los partidos políticos. M éxico: Fondo de Cultura Económica (1975).

ELSTER, J. (1983). U vas amargas. Sobre la subversión de la racionalidad. Barcelona: Península (1988).

FISH M AN , R.M . (1990). Working-Class O rganization and the Return to D emocracy in Spain. Londres: Cornell U niversity Press. 
G ARM EN DIA, J.A. (1988). «La cultura de la empresa: una aproximación teórica y práctica». Revista Española de Investi gaciones Soci ológi cas, 41, p. 7-24.

Gerard, H.B.; WILhelmy, R.A.; Con olley, E.S. «Conformity and group size». Journal of Personality and Social Psychology, 8, p. 79-82.

H IRSCH AAN, A.O . (1984). L'Economie comme science morale et politique. París: GallimardLeSeuil.

- (1982). Interés privado y acción pública. M éxico: Fondo de Cultura Económica (1986).

JuLIÁ, S. (1990). «Sindicatos y poder político en España». Sistema, 97, p. 41-62.

KLIN EberG, O . (1968). «Prejuicio». En EICCSS, vol. 8, p. 423-429. M adrid: Aguilar (1977).

KuHN, T.S. (1962). La estructura de las revoluciones científicas. M éxico: Fondo de Cultura Económica (1971).

LAVE, J. (1988). La cognición en la práctica. Barcelona: Paidós (1991).

LIPSET, S.M .; TROW, M .; COLEM AN, J. (1956). La democracia sindical. La política interna del sindicato tipográfico internacional. M TSS (1989).

Lot M AN, Y. (1973). «El problema de una tipología de la cultura». Semiótica y Praxis.

Barcelona: A. Redondo, p. 71-92.

M ARAVALL, J.M . (1981). La política de la transición 1975-1980. M adrid: Taurus.

M ICHELS, R. (1911). Los partidos políticos. Buenos Aires: Amorrortu (1979).

M ORALES y M ARÍn, J.L. (1984). Diccionario de iconología y s mbología. M adrid: Taurus. M OYA, C. (1984). Señas de L eviatán. Estado nacional y sociedad industrial: España 1936-

1980. M adrid: Alianza.

O LSO N, M . (1965). The logic of collective action. H arvard: H arvard U niversity.

- (1986). Auge y decadencia de las naciones. Barcelona: Ariel.

Panebian Co, A. (1990). M odelos de partido. M adrid: Alianza.

PARAM IO, L. (1988). «El socialismo y los sindicatos: ¿hacia el divorcio?». Sistema, 82, p. $19-36$.

- «Sindicatos y sistema político en España». Si stema, 94-95, p. 73-82.

Pérez D ÍAZ, V. (1987). «ncertidumbres sindicales y ambivalencias obreras. Las varias crisis de la representatividad sindical». El retorno de la sociedad civil. M adrid: IEE. Pizzo Rn O, A. «Sulla razionalità della scelta democratica». Stato e M ercato, 7.

- «Sul confronto intertemporale della utilità». Stato e M ercato, 16.

RED ONDO, N. (1987). «M odernidad y progreso social». El sindicalismo en el siglo XXI. VV.AA. M adrid: Fundación Largo C aballero, p. 279-297.

Regalia, I. (1988). «La participación de los trabajadores en el sindicato. Formas, model os, hipótesis de trabajo». Sociología del Trabajo, 4.

Ripa Perugine, Cesare (1602). I conologia overo descrittione della imagini universali. Milán.

RoRTY, R. (1989). Contingencia, ironía y solidaridad. Barcelona: Paidós (1991).

Rosch, E.; Mervis, C.B.; Gray, W.D.; Johnson, D.M .; Boyes-Braen, P. «Basic $O$ bjects and $N$ atural $C$ ategories». Cognitive Psychology, 8, p. 382-439.

SAH LIN S, M . (1981). H istorical metaphorsand mytical realities. Ann Arbor. U niversity of $\mathrm{M}$ ichigan Press.

- (1976). Cultura y razón práctica. Barcelona: G edisa (1986).

SAN FORD, A.J. (1987). La mente del hombre. M adrid: Alianza, (1990).

SCHANK, R.; ABELSON, R. (1977). Guiones, planes, metas y entendimiento: un estudio de las estructuras del conocimiento humano. Barcelona: Paidós (1987). 
Segre, C. (1977). Semiótica, H istoria y Cultura. Barcelona: Ariel (1981).

SHERIF, M . (1936). The psychology of social norms. N ueva York: H arper and Row.

SherIF, M.; SHERIF, C.W. (1969). Social Psychology. Nueva York: H arper and Row.

T AJFEL, H . (1984). Grupos humanos y categorías sociales. Barcel ona: H erder.

Touraine, A. La M ethode de I'Intervention Sociologique. París: ADIS.

Touraine, A. (1989). «M odernidad y especificidad culturales». Resistencia a la innovación de sistemas complejos. Madrid: ICH .

U GT. (1983). M anual del afiliado. Criterios de organización. Comisión Ejecutiva Confederal. Editado tras el XXXIII C ongreso.

Van DIJK, T.A. (ed.). H andbook of D iscourse Analysis, vol. 1-4. Londres: Academic Press.

- (1984). Prejudice in D iscourse: An Analysis of Ethnic Prejudices In Cognition and Conversation. Amsterdam: J. Benjamins.

Van DIJK, T.A.; KINTCH, W. Strategies of D iscourseC omprehension. Londres: Academic Press.

VV.AA. (1990). Intereses individuales y acción col ectiva. Zona Abierta, 54-55.

W EBER, M . (1922). Economía y Sociedad. M éxico: Fondo de Cultura Económica (1979).

WILDER, D .A. (1986). «Social Categorization: Implications for C reation and Reduction of Intergroup Bias». Advancesin Experimental Social Psychology. En BERKOWITZ, L. (ed.). Vol. 19. N ueva York: Academic Press. 